Accepted version. Paper published as Zwysen (2019). "Different Patterns of Labor Market Integration by Migration Motivation in Europe: The Role of Host Country Human Capital". International Migration Review 53, 1: 59-89

\title{
Different patterns of labour market integration by migration motivation in Europe: the role of host country human capital
}

Wouter Zwysen (wzwyse@ essex.ac.uk), department of Sociology, University of Essex

\section{Abstract}

We study whether individual decisions to invest in the host country, such as taking up training, improving language skills, or naturalisation explain differences in labour market integration between migrants depending on their initial motivation. We use cross-national European data from the 2008 ad-hoc module of the labour force survey and use an estimated dependent variable to analyse migrant gaps in labour market participation, employment, occupational status and employment precariousness. Non-economic migrants, and especially refugees, are less well integrated than economic migrants, but these differences diminish over time due to different rates of and returns to investments in host-country human capital.

\section{Acknowledgements}

This is the pre-peer reviewed version of the following article: Zwysen (sd) "Different patterns of labour market integration by migration motivation in Europe: the role of host country human capital". International Migration Review, which has been published in final form at [link]. This article may be used for non-commercial purposes in accordance with Wiley Terms and Conditions for Self-Archiving.

This work was supported by a Horizon2020 grant (nr. 649255) to the Growth, Equal Opportunities, Migration \& Markets (GEMM) project. 
Accepted version. Paper published as Zwysen (2019). "Different Patterns of Labor Market Integration by Migration Motivation in Europe: The Role of Host Country Human Capital". International Migration Review 53, 1: 59-89

\section{Introduction}

Given increasing public concern about migration and the current refugee crisis across Europe, it is crucial to learn which factors contribute to successful incorporation and whether these factors are the same for migrants regardless of their reason for moving. Traditionally, migrant incorporation is studied as a homogenous process where labour market outcomes improve over time through the acquisition of knowledge about the host country, e.g. better language skills. In this paper we study whether this same pattern holds for economic migrants and non-economic migrants such as those seeking refuge and family migrants.

We use the detailed cross-national data from the 2008 ad-hoc module in the EU Labour Force Survey (LFS) to study differences in labour market integration patterns between several groups of migrants to the EU. We use an estimated dependent variable to measure labour market integration as the gap in terms of participation, employment and job quality compared to similar natives. This allows us to study how these gaps differ between groups of migrants depending on their initial reason for arriving, how they change with years of residence, and the extent to which investments in host-country human capital affect migrants differently in explaining their labour market integration. The next section briefly discusses the literature and our expectations regarding these questions. We then describe the data and the methods used to study this labour market integration.

\section{Conceptual framework}

The focus of this paper is on types of migrants according to their reason for migration. Studies have used different ways to measure migrant motivations depending on the availability of data. A first approach uses information on the country of origin and the period in which someone migrated to impute their likely motivation (Fleischmann and Dronkers, 2010; Kausar and Drinkwater, 2010) or to measure the likelihood of someone being a refugee 
Accepted version. Paper published as Zwysen (2019). "Different Patterns of Labor Market Integration by Migration Motivation in Europe: The Role of Host Country Human Capital". International Migration Review 53, 1: 59-89

through measures of political oppression or stability (as in e.g. Fleischmann and Dronkers, 2010; Spörlein and Van Tubergen, 2014; van Tubergen et al., 2004; ). A second approach uses legal categories of arrival into the country as a way to distinguish between migrants (Aydemir, 2009; Bevelander and Pendakur, 2014; Cortes, 2004; Husted et al., 2009). The benefit is that more is known about the legal context in which they enter the country of residence. The last approach, and the one we follow here, is using self-reported measures of reasons for migration. This is likely to be closer to the true reason for migration than entry visas, as a visa is a legal category which can have substantial implications for the individual and may not always reflect the truth completely (Campbell, 2014; Dumont et al., 2016; Hatton, 2012).

There are substantial differences in outcomes and how they change over time between migrants with different main motivations. In general, migrants arriving for family reasons or as refugees are found to do substantially worse than economic migrants on the labour market (Aydemir, 2009; Bevelander and Pendakur, 2014). Cangiano (2015) uses the same data set we do to analyse labour market integration over different European countries and finds that non-economic migrants are less likely to find employment and when working work on lower quality jobs than other, similarly qualified, migrants. While their paper discusses the role of migration policies, we focus on the individual factors explaining this.

Some studies have addressed differences in how labour market outcomes change with years of residence. These studies mainly focused on refugees and found that, despite their initial disadvantage on the labour market, refugees tend to catch up to other categories of migrants over time (Aydemir, 2009; Campbell, 2014; Cangiano, 2015; Cortes, 2004). A possible reason is that refugees have a longer time horizon than other migrants as they are often not able to return to their country of origin. They are therefore more likely to invest in 
Accepted version. Paper published as Zwysen (2019). "Different Patterns of Labor Market Integration by Migration Motivation in Europe: The Role of Host Country Human Capital". International Migration Review 53, 1: 59-89

host-country human capital such as taking up language training or nationality (Cortes, 2004; Dustmann, 2008).

The literature has put forward several possible reasons for why migration motivation affects labour market integration. Non-economic migrants are thought to be less positively selected in terms of human capital and motivation which results in them doing less well on the labour market compared to economic migrants (e.g. van Tubergen et al., 2004). We then expect that non-economic migrants experience larger penalties on the labour market compared to economic migrants $(\underline{H 1 a})$, but that this gap becomes smaller once differences in individual characteristics and origin are accounted for $(\underline{H 1 b})$. As part of this selection is unobservable some difference would remain.

The resources someone has access to in the country of destination are also likely to differ between types of migrants. Migrants arriving for family reunification for instance generally already have some networks in the country of destination through their partner which could help them find work (Aydemir, 2009). These initial contacts are likely to be important in finding work initially and can affect further integration trajectories. Migrants arriving as students can build up networks and connections during their study which would also put them at more of an advantage compared to those who enter the labour market directly after migration. They are highly qualified and generally obtained these qualifications in the country of residence which would also result in better labour market outcomes Refugees often experienced substantial trauma which can negatively affect their labour market outcomes (Connor, 2010a). Among non-economic migrants we therefore expect students and family migrants to generally do better than refugees $(\underline{H 2 a})$; while among economic migrants those who arrive to fill a certain vacancy and have a guaranteed job upon entry to do better than economic migrants arriving looking for work $(\underline{H 2 b})$. 
Accepted version. Paper published as Zwysen (2019). "Different Patterns of Labor Market Integration by Migration Motivation in Europe: The Role of Host Country Human Capital". International Migration Review 53, 1: 59-89

Whether the main motivation is an economic one is also likely to affect the importance of finding any work to make the migration a success and therefore affect the reservation wage. Luthra, Platt and Salamonska (2016) showed that recently arrived Eastern European migrants differed in how unemployment affected life satisfaction with the effects being far stronger for economic migrants whose success is based on finding work. We expect economic migrants to be more integrated than non-economic migrants with regards to employment, but we would see less clear differences in terms of job quality $(\underline{H 3})$.

Learning the language, taking up host-country nationality or obtaining qualifications or training are forms of human capital that can be specific to the country of residence. Investing in these would decrease the difference in labour market outcomes between migrants and natives. We call these decisions choices or investments because they require a deliberate decision; cost time, effort and sometimes money; and bring about an expected return on the labour market (Chiswick, 2009; Cortes, 2004; De Vroome and van Tubergen, 2010). This is not to say that these decisions are necessarily a 'free' choice. There can be substantial constraints - low skilled migrants may not have the financial resources or accrue them over a longer period of time to be able to acquire receiving society specific investments such as language skills, qualifications, job training or citizenship (Barry, 2001).

Part of the reason why labour market integration improves over time is thought to be precisely because these types of host-country human capital are accumulated with time (Alba and Nee, 1997). In this paper we study whether this process occurs similarly for all migrants and whether these types of host-country human capital investment have the same effect on different aspects of labour market integration. As mentioned earlier, there are differences between migrants depending on their reason for migration in the take-up of host-country nationality or the improvement of language skills (Cortes, 2004; Dumont et al., 2016). Groups that invest more heavily, because they have a longer time horizon for instance, would 
Accepted version. Paper published as Zwysen (2019). "Different Patterns of Labor Market Integration by Migration Motivation in Europe: The Role of Host Country Human Capital". International Migration Review 53, 1: 59-89

then experience the fastest trajectory towards equity with natives. Accepted refugees also tend to benefit from more public assistance and can be naturalised upon regularisation (Bevelander and Pendakur, 2014). This leads to the expectation that especially refugees, but also migrants arriving for family reasons who can be expected to have a longer time horizon on average than economic migrants, experience a faster growth in labour market integration with years of residence $(\underline{H 4 a})$ than other migrants. These differences in growth over time would then be reduced by including host-country human capital characteristics $(\underline{H 4 b})$.

The role of host-country human capital in explaining differences between types of migrants has mainly been studied in the US, focusing on refugees. Connor (2010a) finds that refugees are $60 \%$ less likely than economic migrants to work on a skilled job and earn $19 \%$ less than economic migrants. Differences in language ability, being schooled in the US and to a lesser extent health and neighbourhood location differences accounted for up to $50 \%$ of this disadvantage. Cortes (2004) shows that the annual earnings of refugees rise faster than those of economic immigrants which is partly due to their higher improvement in language skills.

Besides different rates of investment, there may also be differences in the returns to these investments between migrants. Host-country human capital may be more beneficial for otherwise more disadvantaged groups as it provides a strong signal that can overrides the mainly negative view. Naturalisation is for instance found to affect disadvantaged migrants more positively than the more advantaged (Corluy et al., 2011). Non-economic migrants are also likely to be less well matched to the host-country labour market initially and would therefore benefit more from further investment than economic migrants. We then expect that non-economic migrants and especially refugees benefit more from having higher hostcountry human capital than economic migrants $(\underline{H 5})$.

Higher host-country human capital is expected to be positively associated with job quality, but would not necessarily improve employment probability $(\underline{H 6 a})$. Many migrants 
Accepted version. Paper published as Zwysen (2019). "Different Patterns of Labor Market Integration by Migration Motivation in Europe: The Role of Host Country Human Capital". International Migration Review 53, 1: 59-89

generally find work in lower-skilled sectors where high human capital is not required (e.g. Reyneri and Fullin, 2011). Higher host-country human capital may even have a negative effect as it drives reservation wages up and lowers the probability of taking low-quality work. If this mechanism holds we would expect a lower employment probability, but especially for economic migrants rather than non-economic migrants as the former are expected to have lower reservation wages initially $(\underline{H 6 b})$.

\section{Data and variables}

We test these hypotheses in a comparative way using the 2008 ad-hoc module of the European LFS. This is a large-scale harmonized survey in European countries and produces reliable estimates in terms of stocks of non-nationals despite not primarily targeting migrants (Martí and Ródenas, 2007). The 2008 ad-hoc module provides information on the experiences of migrants and contains harmonized questions on the main reason for migration, perceptions of language skills, use of services and whether migrants naturalised.

The sample for the main analyses is restricted to first generation migrants who were not nationals at birth, aged 25 to 65 . After listwise deletion of observations with missing values our sample includes 20,198 migrants in 14 countries. ${ }^{1}$ Descriptive statistics for all variables and the estimated outcome variables are shown in tables A1 (for women) and A2 (for men) in the supplementary material.

We study four labour market outcomes. The first two are participation on the labour market (binary) and employment (binary). While employment of migrants likely matters most to public opinion the quality of work is also crucial for full integration. We study the occupational status of jobs through the ISEI scale, a socio-economic indicator ranging from 16 (lowest) to 90 (highest), imputed through 3-digit occupational codes (Ganzeboom and

\footnotetext{
1 Austria, Belgium, Germany, Spain, France, Greece, Ireland, Italy, Luxembourg, Netherlands, Norway, Portugal, Sweden and the UK
} 
Accepted version. Paper published as Zwysen (2019). "Different Patterns of Labor Market Integration by Migration Motivation in Europe: The Role of Host Country Human Capital". International Migration Review 53, 1: 59-89

Treiman, 1996). We also include a binary variable for working on an involuntary nonstandard contract, showing precarious work (Buchholz et al., 2009). This "bad job" dummy indicates that someone works part-time but wants to work more hours or works on a temporary contract because a permanent position was not available.

We include six categories for migration motivation, measuring the primary reason. First, there are two types of economic migrants: those who arrive as intra corporate transfers or who had a job ready prior to migration; and those who arrive to look for work. Noneconomic migrants are separated in three groups: migrants who arrived as students and remained; those seeking international protection; and migrants arriving for family formation or reunification. Finally we include a rest category of migrants with other motives.

To measure labour market integration over time we include years of residence. This is reported as exact years until 10 and afterwards as 5 year intervals for which the midpoint is imputed so the variable can be treated as continuous.

One of the main reasons why migrants are expected to get lower returns to their qualifications is that there is more uncertainty about their skills (e.g. Chiswick and Miller, 2008; Reyneri and Fullin, 2011). We include two dummy variables to proxy an investment towards reducing this uncertainty (Basilio et al., 2014; Battu and Sloane, 2004; De Vroome and van Tubergen, 2010). First, whether someone followed any training or other courses in the last 4 weeks; and second whether someone either obtained their highest qualifications in the country of residence or has taken steps towards equivalising their qualifications obtained abroad.

Speaking the language well is crucial for further integration and often a requirement for finding good employment and making use of public services, bringing substantial returns on the labour market (Campbell, 2014; Cebulla et al., 2010; Cheung, 2013; Cortes, 2004; Dustmann and Fabbri, 2003). The ad-hoc module includes a question on whether respondents 
Accepted version. Paper published as Zwysen (2019). "Different Patterns of Labor Market Integration by Migration Motivation in Europe: The Role of Host Country Human Capital". International Migration Review 53, 1: 59-89

feel they need to improve their language skills to get an appropriate job which is reversed to indicate good language skills. The question is not ideal but it does indicate an assessment of the own language skills.

As a final indicator of investments in the country of residence we include a dummy for taking up the nationality after the age of 16 . This provides a strong signal on the labour market and is associated with better outcomes (Corluy et al., 2011). Migrants who had nationality at birth are not included in the analyses. Previous studies found that less advantaged migrants are more likely to naturalise (Vink et al., 2013) and that refugees tend to have higher returns to naturalization in terms of employment (Dumont et al., 2016). As a robustness test we restrict the sample to migrants who were in the country longer than 10 years as it is normally possible to naturalise in all countries considered here (Dumont et al., 2016). We find no substantial differences.

Table 1 below shows the distribution of these variables over motivation groups. The majority of male migrants are economic while among women almost half arrive for family reasons. There are substantial differences between groups in their host-country human capital. As expected, student migrants have very high levels of human capital, especially following training and having equivalent qualifications. Overall, economic migrants without a job ready stand out as having relatively low scores on all types of investment while migrants who arrived with a job have generally higher human capital. Migrants seeking protection and family migrants have relatively poor language skills, but score high on other types of human capital investments with particularly refugees very likely to take up hostcountry nationality.

[Table 1 around here]

In this paper we measure labour market integration as the difference in labour market outcomes of migrants and that of similar natives. This is done using coarsened exact 
Accepted version. Paper published as Zwysen (2019). "Different Patterns of Labor Market Integration by Migration Motivation in Europe: The Role of Host Country Human Capital". International Migration Review 53, 1: 59-89

matching (Iacus et al., 2012) as explained further in the methods section. The variables on which migrants are matched to natives are the region at NUTS level ${ }^{2}$, age $^{3}$, gender, whether they are married, and qualifications ${ }^{4}$. Besides including these control variables in the models to account for remaining differences (Iacus et al., 2012) we also control for certain characteristics of the origin countries.

One of the problems with the European labour force survey is that country of birth is only provided in highly aggregated groups ${ }^{5}$. As these groups are associated with migrant motivation and not directly meaningful we do not include them, but use relevant characteristics from the sending region, calculated as the average of the values for the relevantcountries, weighted by the share of migrants that each country makes up of the total amount of migrants from that region in a given country of destination. The shares are obtained by the Database on Immigrants in OECD Countries (DIOC) from 2010.

The share of Christians in the sending country, obtained through the world religion dataset for the year 2005 (Maoz and Henderson, 2013), is used to indicate religious closeness to the receiving country. We also include female labour force participation and the share of graduates (Fleischmann and Dronkers, 2010; van Tubergen et al., 2004). Following van Tubergen et al. (2004) we include two ratio variables (in logarithmic form) to capture selection. The ratio of the Gini coefficient in the sending region to that of the receiving country is used to indicate selection based on whether migrants assume they will do relatively better (worse) in a more equal country, based on their perception of whether they would be at

\footnotetext{
2 1-digit NUTS level: 3 in Austria; 3 in Belgium; 16 in Germany; 7 in Spain; 8 in France; 4 in Greece; 2 in Ireland; 5 in Italy; 1 in Luxembourg, 1 in the Netherlands; 7 in Norway; 5 in Portugal; 3 in Sweden; 11 in UK

${ }^{3}$ Age is measured in 5-year intervals from 25 to 64.

47 ISCED codes ranging from pre-primary/ no degree to upper tertiary.

5 Categories are: "own country", "EU15", "NMS10", "NMS3", "EFTA", "Other Europe", "North Africa" "Other Africa", "Near Middle East", "East Asia", "South and South-East Asia", "North America", "Central America", "South America", Australia/Oceania", "Latin America" with some countries have further aggregations of all new member states; EFTA and other Europe; North Africa and the Near Middle East; South and East Asia; North America and Australia.
} 
Accepted version. Paper published as Zwysen (2019). "Different Patterns of Labor Market Integration by Migration Motivation in Europe: The Role of Host Country Human Capital". International Migration Review 53, 1: 59-89

the higher or lower end of the distribution. The ratio of GDP per capita indicates whether migrants move from more to less developed areas or the reverse.

The share of graduates, female labour force participation, Gini coefficient and GDP per capita (in current US dollars) are all obtained from the World Bank ${ }^{6}$. As a final indicator we include a dummy for being born in a current EU member state.

\section{Methods}

Full labour market integration would mean migrants have the same opportunities as natives. The difference in observed outcomes between migrants and similar natives, or migrant gaps, would then be smaller for a more integrated migrant (Algan et al., 2010).

We estimate this gap directly and then aim to explain the differences in labour market integration for groups of migrants by years of residence and investment in human capital. A similar 2-stage method was used by Connor (2010b) to study gaps in religiosity between Muslim migrants and natives. We use coarsened exact matching to calculate the difference between a migrant (treated) and similar natives (controls) within strata consisting of observed characteristics after coarsening continuous variables into categories (Iacus et al., 2012). By equalising the distribution of covariates between migrants and natives we do not have to rely on extrapolation through modelling assumptions and potential non-linearity is taken into account.

We used 483,707 natives in the LFS to form counterfactuals, divided over 6,322 strata made up of combinations of region, age, gender, marital status and qualifications, in which both natives (at least 5) and migrants were present. Within each strata the average labour force participation, employment rate, occupational status and share of involuntary nonstandard contracts among natives was computed.

\footnotetext{
${ }^{6}$ http://data.worldbank.org/indicator, accessed 18/03/2016. Values from 2008 are used (and average of 20072009 if 2008 was not available)
} 
Accepted version. Paper published as Zwysen (2019). "Different Patterns of Labor Market Integration by Migration Motivation in Europe: The Role of Host Country Human Capital". International Migration Review 53, 1: 59-89

In the second step, this difference between the observed outcome for a migrant and this average outcome among similar natives is the dependent variable in linear regression models. We use robust standard errors, clustered at the regional level, to account for the higher measurement error introduced by using an estimated dependent variable (Lewis and Linzer, 2005). Analyses are carried out separately by gender as men and women differ in their labour market integration patterns and it is also difficult to separate family from refugee migrants among women (Dumont et al., 2016). All analyses are weighted using the weights provided by the EU LFS.

We ask two main questions: first about the different patterns in labour market integration for migrants with different motivations; and second about the effects of hostcountry human capital and the degree to which they explain these differences. The first question is answered through estimating equation 1.

$\mathrm{D}\left(\mathrm{Y}_{\mathrm{is}}-\hat{\mathrm{Y}}_{\mathrm{s}}\right)=\alpha+\beta_{1} * \mathrm{REAS}+\beta_{2} * \mathrm{X}+\beta_{3} * \mathrm{D}+\beta_{4} *$ YEARS $+\beta_{5} *$ YEARS $*$ YEARS + $\gamma_{1} *$ REAS*YEARS $+\gamma_{2} *$ REAS*YEARS $*$ YEARS $+\varepsilon$

The outcome variable is the difference between the observed outcome and the counterfactual among similar natives, which is estimated. The main variable of interest is the reason for migration (REAS). $\mathrm{X}$ is a vector of controls including marital status, education and age (squared) as well as controls for the sending region characteristics. D is a vector of dummies for country of destination. Length of residence is included (YEARS) and to allow for non-linear trajectories we also include its square. Years of migration (squared) is interacted with main motivation for migration through interaction terms $\gamma_{1}$ and $\gamma_{2}$. To facilitate the interpretation of results we study marginal effects and predicted probabilities.

$\mathrm{D}\left(\mathrm{Y}_{\mathrm{is}}-\hat{\mathrm{Y}}_{\mathrm{s}}\right)=\alpha+\beta{ }^{\prime}{ }_{1}{ }^{*} \mathrm{REAS}+\beta^{\prime}{ }_{2}{ }^{*} \mathrm{X}+\beta^{\prime}{ }_{3}{ }^{*} \mathrm{D}+\beta{ }^{\prime}{ }_{4}$ Y YEARS $+\beta{ }^{\prime}{ }_{5}{ }^{*}$ YEARS $*$ YEARS + $\gamma^{\prime}{ }_{1} * \mathrm{REAS}^{*}$ YEARS $+\gamma^{\prime}{ }_{2} * \mathrm{REAS}^{*}$ YEARS $*$ YEARS $+\delta_{1} * \mathrm{HC}+\delta_{1} *$ REAS*HC $+\varepsilon$ 
Accepted version. Paper published as Zwysen (2019). "Different Patterns of Labor Market Integration by Migration Motivation in Europe: The Role of Host Country Human Capital". International Migration Review 53, 1: 59-89

Equation 2 includes the indicators of host-country human capital (HC), allowing for different effects depending on main migration motivation. This model allows us to test whether part of the differences between migrant groups or in their trajectories over time is mediated by host-country human capital. This can be done by comparing the coefficients, and estimated effects given the different interactions, in equation 1 to those in equation 2 . A reduction in these effects would indicate that part of the differences is due to a different investments (Mackinnon and Dwyer, 1993). The coefficients $\delta_{1}$ also test whether the returns to host-country human capital investments differ by motivation.

\section{Results}

Figure 1 below shows the estimated gap in labour market outcomes between migrants and natives. The bars indicate the average difference, only accounting for country fixed effects; while the symbols show the difference between migrants and similar natives after matching with the $95 \%$ confidence intervals. Table A3 in the supplementary material shows the numbers as well as the averages for economic and non-economic migrants.

We find that economic migrants are more integrated than non-economic migrants in terms of employment as employment gaps are 3 and 6 percentage points smaller for men and women respectively. There is no clear difference in terms of job quality however, supporting hypothesis 3 . We also find that the groups that are likely to have access to more resources upon migration do better than those that did not, supporting hypothesis 2. Economic migrants with a contract outperform economic migrants who arrive without work on all outcomes except for employment among women. Refugees are less integrated than student or family migrants on all outcomes.

[Figure 1 around here] 
Accepted version. Paper published as Zwysen (2019). "Different Patterns of Labor Market Integration by Migration Motivation in Europe: The Role of Host Country Human Capital". International Migration Review 53, 1: 59-89

We hypothesized that accounting for composition would diminish some of the differences between groups of migrants as it accounts for partly for selection. The difference between the highest and lowest gap decreases for activity among women by 4 p.p.; for employment by 4 p.p. for men and 2 p.p. for women; and in occupational status by 11-15 ISEI points. Matching does not reduce the difference in working on a bad job however. We therefore find some support for hypothesis $1 \mathrm{~b}$ as compositional factors do account for part of the difference in integration in terms of activity, employment and occupational status by motivation.

These average differences hide changes with years of residence. We briefly discuss the estimated patterns here and they are shown in figures A1 and A2 in the supplementary material. Migrants remain more likely to be active on the labour market than natives regardless of years of residence. In the other outcomes there is convergence to natives over time although gaps remain, especially with regards to occupational status and non-standard work for men. Refugees generally experience the largest initial gaps and catch up slowly over time, consistent with the literature (e.g. Cangiano, 2015; Cortes, 2004). Employment gaps are largest initially for non-economic migrants, but in terms of occupational status the most disadvantaged group are economic migrants without a contract who experience large gaps and do not catch up to other groups. The interactions between reason for migration and years of residence (squared) are only jointly statistically significant (at $\mathrm{p}<0.05$ ) for activity for female immigrants and employment and working on an involuntary non-standard contract for men.

Table 2 shows the effects of an extra year of residence, estimated at 5 years of residence, before and after including host-country human capital in the regression models as described by equations 1 and 2 resp. in the methods section. It also shows the reduction in the effect (in percentage) after including host-country human capital. These effects are shown 
Accepted version. Paper published as Zwysen (2019). "Different Patterns of Labor Market Integration by Migration Motivation in Europe: The Role of Host Country Human Capital". International Migration Review 53, 1: 59-89

graphically in figure A3 at 5 years of residence and figure A4 at 15 years of residence in the supplementary material. We find similar patterns when studying the effect of an extra year of residence at 15 years of residence although the effects are generally smaller. Full coefficients are shown in table A4 in the supplementary material.

[Table 2 around here]

As expected, non-economic migrants and in particular refugees make the most progress over time while economic migrants see less change over time. As student migrants also make large gains hypothesis $4 \mathrm{a}$ is only partially supported however. We also find that substantial parts of this increase in labour market integration are diminished when hostcountry human capital is taken into account, especially for refugees and more strongly for women than for men. Host-country human capital mainly explains changes in job quality over time. Substantial parts of the estimated increase in occupational status over years of residence disappear when controlling for host-country human capital and the effect is reduced by up to $87 \%$ in the case of female refugees.

Including host-country human capital reduces the effect of years of residence on employment more for non-economic migrants than economic migrants. This could indicate that the benefit in employability is outweighed by rising reservation wages for economic migrants. Including host-country human capital does not really reduce the overall differences in effects of years of residence by main motivation however, with the exception of activity. We therefore partly accept hypothesis $4 \mathrm{~b}$, as some of the effect of years of residence is indeed accounted for by host-country human capital, especially for non-economic migrants in employment and in job quality, but the overall variability does not diminish.

Finally we study how the effects of host-country human capital affect labour market integration. We briefly discuss the effects of individual investments by motivation, shown in figures 2 and 3. 
Accepted version. Paper published as Zwysen (2019). "Different Patterns of Labor Market Integration by Migration Motivation in Europe: The Role of Host Country Human Capital". International Migration Review 53, 1: 59-89

[Figure 2 around here]

[Figure 3 around here]

The effects of these types of host-country human capital vary substantially between groups. We find that all types of investment tend to be positively associated with occupational status with some exceptions by groups. Having recently attended a course is not associated with higher status jobs for male refugee and family migrants and having better language skills also does not affect the status of jobs for male student or family migrants. Attending training and naturalization is negatively associated with employment for male refugees and female economic migrants with a contract upon arrival. Having equivalent qualifications is strongly positively associated with employment for male refugee and female family migrants.

To interpret the effects of host-country human capital more fully, figure 4 shows the estimated penalty for migrants with low host-country human capital (reporting needing better language skills; not naturalized and no equivalent qualifications) and those with high hostcountry human capital (no language problems, equivalised qualifications and naturalized). We do not include having attended training recently as fewer migrants have done this. In our sample, $7.4 \%(2,228)$ have low host-country human capital while $12.6 \%(3,777)$ have high host-country human capital. The values and the difference between them are shown in table A5 in the supplementary material.

[Figure 4 around here]

A first observation is that migrant penalties are generally substantially smaller for migrants with high than for those with low host-country human capital although there are variations between groups. The largest gains in activity and employment are made by refugee and family migrants. Regarding job quality the difference between high and low host-country human capital is very large for student and refugee migrants, but it also matters a lot for 
Accepted version. Paper published as Zwysen (2019). "Different Patterns of Labor Market Integration by Migration Motivation in Europe: The Role of Host Country Human Capital". International Migration Review 53, 1: 59-89

economic migrants who arrive seeking work. A second observation is that, especially with regards to being active on the labour market and employment, but to a lesser extent also for job quality indicators, the difference in penalty by main motivation is smaller for migrants with high than for those with low host-country human capital.

Having equivalent qualifications, speaking the language well and being naturalized, seem to take away some of the uncertainty and disadvantage that may otherwise differentiate more between different types of migrants. Among migrants who lack these resources penalties can be quite severe however, with family and refugee migrants being 7 to 20 p.p. less likely to be employed than similar natives; occupational status gaps ranging from 7 to 16 ISEI-points and especially non-economic migrants being much more likely to work on involuntary non-standard job contracts than similar natives.

High human capital in the country of residence is associated with doing better in terms of labour market outcomes, although gaps remain. These investments are particularly important for the more disadvantaged groups such as refugees and family migrants where they are important in gaining access to the labour market in the first place as well as in job quality, support hypothesis 5. In support of hypothesis 6a we find that differences between those with high and low host-country human capital are relatively larger for job quality than for the probability of employment or being economically active. The benefits of host-country human capital on employment are mainly present for non-economic migrants while for economic migrants the effect is smaller or even negative. This supports hypothesis $6 b$, indicating that higher capital might increase the reservation wage, leading to higher unemployment but also higher quality work. 
Accepted version. Paper published as Zwysen (2019). "Different Patterns of Labor Market Integration by Migration Motivation in Europe: The Role of Host Country Human Capital". International Migration Review 53, 1: 59-89

\section{Limitations and Robustness tests}

In this section we briefly discuss the limitations of the data and these analyses and show results from two sensitivity analyses. As the LFS is a cross-sectional dataset we cannot study the actual accumulation of host-country human capital and changing labour market integration over time, but only compare migrants who arrived in different years. Different attrition probabilities could be the reason for converging between migrant groups over time, rather than a catching up of non-economic migrants. We might also capture changes between cohorts of migrants rather than over time. To assess the sensitivity of our results to this time dimension, we estimate the full model (equation 2) again on a subsample of migrants who have remained in the country for 10 years or longer. We hypothesize that the different return probabilities are less of an issue in this sample of people who stayed relatively long already. While the regulations regarding naturalisation differ over European countries, it is generally an available option for those who remained in the country of destination for longer than 10 years (Dumont et al., 2016). This sample therefore also allows us to estimate the effect of naturalization more robustly.

As a second test we restrict the analyses to only non-EU migrants. This is important as EU migrants have more extensive legal rights of residence and work than non-EU citizens and often entered via different ways.

The estimated effects of an extra year of residence and of the indicators of hostcountry human capital (from equation 2) on employment and occupational status are shown in table A6 and table A7 in the supplementary material. Full results are available on request with the author.

While there are some variations between models there are generally no substantial differences in the trajectory over time or the effects of host-country human capital between the different models, although as the sample is smaller effects are not always statistically 
Accepted version. Paper published as Zwysen (2019). "Different Patterns of Labor Market Integration by Migration Motivation in Europe: The Role of Host Country Human Capital". International Migration Review 53, 1: 59-89

significant. There is some difference in the effect of naturalisation for male refugees however where their benefit in occupational status disappears in the subsample of migrants 10 years after residence. This means that they benefit especially from naturalisation relatively shortly after arrival which may be because naturalisation then may indicate more governmental support that assists in finding better jobs. This shows our results are relatively robust to different specifications are not only driven by relatively recent migrants or by EU migrants.

A final important point is that integration patterns for different motivation groups likely depend strongly on the national context. In a recent joint report by the OECD and the European Commission it was shown that refugees tend to do relatively better in countries where they are fewer, such as in Spain (Dumont et al., 2016). Cangiano (2015) discusses the differences between countries and their policies in more detail, showing that there are substantial differences between countries in the composition of migrants, the support they receive, and the relative gaps. They find little difference between economic and noneconomic migrants in Spain and Italy, while in countries that prioritise non-economic migrants such as Germany, France and Sweden these are much more at risk of overqualification. In this paper we focused instead on the mechanisms leading to differences between motivation groups and only accounted for the country of residence as also studying policy differences is beyond the scope for this work.

\section{Conclusion}

We set out to study whether the motivation with which a migrant originally arrived in a European country affects their labour market integration and whether these differences are due to investments in the host-country human capital. This paper shows the importance of considering the heterogeneity by motivation among migrants. We find that migrants who arrived looking for work experience smaller employment gaps than those that arrived for 
Accepted version. Paper published as Zwysen (2019). "Different Patterns of Labor Market Integration by Migration Motivation in Europe: The Role of Host Country Human Capital". International Migration Review 53, 1: 59-89

family reasons, to study, or seeking refuge. There are less clear differences between these two groups in terms of job quality however as we find that economic migrants who arrived without a contract at the time of entry tend to work on substantially lower-quality jobs than natives and experience less upward integration over time than non-economic migrants. We find some support for the idea that those migrants who have more resources upon entry also do better on the labour market compared to natives, even after accounting for individual characteristics.

We found that family and refugee migrants are generally quite disadvantaged in the earlier years after migration, but the gaps with other migrants diminish over time. This is especially the case for their probability of being employed. Part of this catching-up is due to differences in the probability of being naturalised, taking up extra education or equivalising qualifications, and language skills. We also find that these types of investment in the hostcountry human capital have larger effects for the generally more disadvantaged migrants who arrive for family reasons or fleeing violence, although they affect the quality of work for all migrants.

A reason for this may be that these investments provide a strong signal, which is especially beneficial to those with lower skills and from a more disadvantaged group who may face more statistical discrimination and whose skills are less matched with the requirements of the country of origin. We find that the differences between migrant groups are particularly large among migrants with low language skills, qualifications that are not recognised in the country and without host-country nationality. Among those with higher host-country human capital the differences between motivation groups are substantially smaller however. 
Accepted version. Paper published as Zwysen (2019). "Different Patterns of Labor Market Integration by Migration Motivation in Europe: The Role of Host Country Human Capital". International Migration Review 53, 1: 59-89

\section{References}

Alba, R., and Nee, V. (1997). Rethinking assimilation theory for a new era of immigration. International Migration Review 31, 826-874.

Algan, Y., Dustmann, C., Glitz, A., and Manning, A. (2010). The economic situation of first and second-generation immigrants in france, germany and the united kingdom*. The Economic Journal 120, F4-F30.

Aydemir, A. (2009). Immigrant selection and short-term labor market outcomes by visa category. J Popul Econ 24, 451-475.

Barry, B. (2001). Culture and Equality: An Egalitarian Critique of Multiculturalism (Cambridge, UK: Polity).

Basilio, L., Bauer, T.K., and Kramer, A. (2014). Transferability of Human Capital and Immigrant Assimilation: An Analysis for Germany. SOEPpapers on Multidisciplinary Panel Data Research 1-37.

Battu, H., and Sloane, P.J. (2004). Over-education and ethnic minorities in Britain. The Manchester School 72, 535-559.

Bevelander, P., and Pendakur, R. (2014). The labour market integration of refugee and family reunion immigrants: a comparison of outcomes in canada and sweden. Journal of Ethnic and Migration Studies 40, 689-709.

Buchholz, S., Hofäcker, D., Mills, M., Blossfeld, H.-P., Kurz, K., and Hofmeister, H. (2009). Life courses in the globalization process: the development of social inequalities in modern societies. European Sociological Review 25, 53-71.

Campbell, S. (2014). Does it matter why immigrants came here? Original motives, the labour market, and national identity in the uk. DQSS Working Paper 65. 
Accepted version. Paper published as Zwysen (2019). "Different Patterns of Labor Market Integration by Migration Motivation in Europe: The Role of Host Country Human Capital". International Migration Review 53, 1: 59-89

Cangiano, A. (2015). Migration policies and migrant employment outcomes. CMS 2, 417-443.

Cebulla, A., Daniel, M., Zurawan, A., Brown, V., Tipping, S., and Tomaszewski, W. (2010). Spotlight on refugee integration: findings from the survey of new refugees in the United Kingdom (London, UK: Home Office and UK Visas and Immigration).

Cheung, S.Y. (2013). Ethno-religious minorities and labour market integration: generational advancement or decline? Ethnic and Racial Studies 37, 140-160.

Chiswick, C.U. (2009). The economic determinants of ethnic assimilation. Journal of Population Economics 22, 859-880.

Chiswick, B.R., and Miller, P.W. (2008). Why is the payoff to schooling smaller for immigrants? Labour Economics 15, 1317-1340.

Connor, P. (2010a). Explaining the refugee gap: economic outcomes of refugees versus other immigrants. Journal of Refugee Studies 23, 377-397.

Connor, P. (2010b). Contexts of immigrant receptivity and immigrant religious outcomes: the case of muslims in western europe. Ethnic and Racial Studies 33, 376-403.

Corluy, V., Marx, I., and Verbist, G. (2011). Employment chances and changes of immigrants in belgium: the impact of citizenship. International Journal of Comparative Sociology 52, 350-368.

Cortes, K.E. (2004). Are refugees different from economic immigrants? Some empirical evidence on the heterogeneity of immigrant groups in the united states. Review of Economics and Statistics 86, 465-480.

De Vroome, T., and van Tubergen, F. (2010). The employment experience of refugees in the Netherlands. International Migration Review 44, 376-403. 
Accepted version. Paper published as Zwysen (2019). "Different Patterns of Labor Market Integration by Migration Motivation in Europe: The Role of Host Country Human Capital". International Migration Review 53, 1: 59-89

Dumont, J.-C., Liebig, T., Preschner, J., Tanay, F., and Xenogiani, T. (2016). How are refugees faring on the labour market in Europe? (Brussels, Belgium: European Commission and OECD).

Dustmann, C. (2008). Return migration, investment in children, and intergenerational mobility comparing sons of foreign- and native-born fathers. Journal of Human Resources 43, 299-324.

Dustmann, C., and Fabbri, F. (2003). Language proficiency and labour market performance of immigrants in the $\mathrm{uk}^{*}$. The Economic Journal 113, 695-717.

Fleischmann, F., and Dronkers, J. (2010). Unemployment among immigrants in European labour markets: an analysis of origin and destination effects. Work Employment Society $24,337-354$.

Ganzeboom, H.B.G., and Treiman, D.J. (1996). Internationally comparable measures of occupational status for the 1988 international standard classification of occupations. Social Science Research 25, 201-239.

Hatton, T.J. (2012). Refugee and asylum migration to the oecd: a short overview. IZA Discussion Paper Series.

Husted, L., Heinesen, E., and Andersen, S.H. (2009). Labour market integration of immigrants: estimating local authority effects. Journal of Population Economics 22, 909-939.

Iacus, S.M., King, G., and Porro, G. (2012). Causal inference without balance checking: coarsened exact matching. Political Analysis 20,1-24.

Kausar, R., and Drinkwater, S. (2010). Who performs better? A comparison of earnings and occupational attainment of refugees and asylum seekers and economic immigrants in the uk (University of Surrey).

Lewis, J.B., and Linzer, D.A. (2005). Estimating regression models in which the dependent variable is based on estimates. Political Analysis 13, 345-364. 
Accepted version. Paper published as Zwysen (2019). "Different Patterns of Labor Market Integration by Migration Motivation in Europe: The Role of Host Country Human Capital". International Migration Review 53, 1: 59-89

Luthra, R., Platt, L., and Salamońska, J. (2016). Types of Migration: The Motivations, Composition, and Early Integration Patterns of "New Migrants" in Europe. Int Migr Rev n/an/a.

Mackinnon, D.P., and Dwyer, J.H. (1993). Estimating mediated effects in prevention studies. Evaluation Review 17, 144-158.

Maoz, Z., and Henderson, E.A. (2013). The world religion dataset, 1945-2010: logic, estimates, and trends. International Interactions 39, 265-291.

Martí, M., and Ródenas, C. (2007). Migration Estimation Based on the Labour Force Survey: An EU-15 Perspective. The International Migration Review 41, 101-126.

Reyneri, E., and Fullin, G. (2011). Labour market penalties of new immigrants in new and old receiving west european countries. International Migration 49, 31-57.

van Tubergen, F., Maas, I., and Flap, H. (2004). The economic incorporation of immigrants in 18 western societies: origin, destination, and community effects. American Sociological Review 69, 704-727.

Vink, M.P., Prokic-Breuer, T., and Dronkers, J. (2013). Immigrant naturalization in the context of institutional diversity: policy matters, but to whom? Int Migr 51, 1-20. 
Accepted version. Paper published as Zwysen (2019). "Different Patterns of Labor Market Integration by Migration Motivation in Europe: The Role of Host Country Human Capital". International Migration Review 53, 1: 59-89

\section{List of tables}

\begin{tabular}{|c|c|c|c|c|c|c|}
\hline $\begin{array}{l}\text { Men } \\
(\mathrm{N}=10,391)\end{array}$ & $\begin{array}{l}\text { Years of } \\
\text { residence }\end{array}$ & $\begin{array}{l}\text { Training } \\
\text { course }\end{array}$ & Equivalised & $\begin{array}{l}\text { Language } \\
\text { skills }\end{array}$ & Naturalised & Share \\
\hline $\begin{array}{l}\text { Employment } \\
\text { job }\end{array}$ & 14.3 & $7.1 \%$ & $26.4 \%$ & $84.9 \%$ & $12.6 \%$ & $17.0 \%$ \\
\hline $\begin{array}{l}\text { Employment no } \\
\text { job }\end{array}$ & 13.3 & $2.8 \%$ & $15.7 \%$ & $78.1 \%$ & $14.0 \%$ & $34.7 \%$ \\
\hline Study & 16.4 & $16.3 \%$ & $81.7 \%$ & $90.8 \%$ & $33.7 \%$ & $6.2 \%$ \\
\hline Refugee & 15.2 & $7.0 \%$ & $46.6 \%$ & $75.6 \%$ & $60.3 \%$ & $10.3 \%$ \\
\hline Family & 15.9 & $7.8 \%$ & $41.1 \%$ & $84.3 \%$ & $34.6 \%$ & $21.8 \%$ \\
\hline Other & 16.0 & $7.3 \%$ & $37.5 \%$ & $86.3 \%$ & $30.0 \%$ & $10.1 \%$ \\
\hline $\begin{array}{l}\text { Women } \\
(N=9,807)\end{array}$ & & & & & & \\
\hline $\begin{array}{l}\text { Employment } \\
\text { job }\end{array}$ & 14.0 & $11.5 \%$ & $37.2 \%$ & $83.1 \%$ & $14.8 \%$ & $9.4 \%$ \\
\hline $\begin{array}{l}\text { Employment no } \\
\text { job }\end{array}$ & 12.2 & $4.7 \%$ & $21.1 \%$ & $78.9 \%$ & $15.1 \%$ & $20.4 \%$ \\
\hline Study & 15.0 & $19.6 \%$ & $76.8 \%$ & $88.5 \%$ & $27.7 \%$ & $5.7 \%$ \\
\hline Refugee & 15.4 & $9.6 \%$ & $45.9 \%$ & $71.3 \%$ & $67.0 \%$ & $6.4 \%$ \\
\hline Family & 16.0 & $9.7 \%$ & $40.7 \%$ & $80.4 \%$ & $37.2 \%$ & $48.1 \%$ \\
\hline Other & 15.5 & $9.6 \%$ & $43.2 \%$ & $84.1 \%$ & $32.4 \%$ & $10.0 \%$ \\
\hline
\end{tabular}

Source: LFS ad-hoc module 2008 for migrants aged 25-65 and having been in the country of residence longer than 5 years. 
Accepted version. Paper published as Zwysen (2019). "Different Patterns of Labor Market Integration by Migration Motivation in Europe: The Role of Host Country Human Capital”. International Migration Review 53, 1: $59-89$

Table 2: Effect of extra years of residence at 5 years before including human capital investment and \% explained by including it.

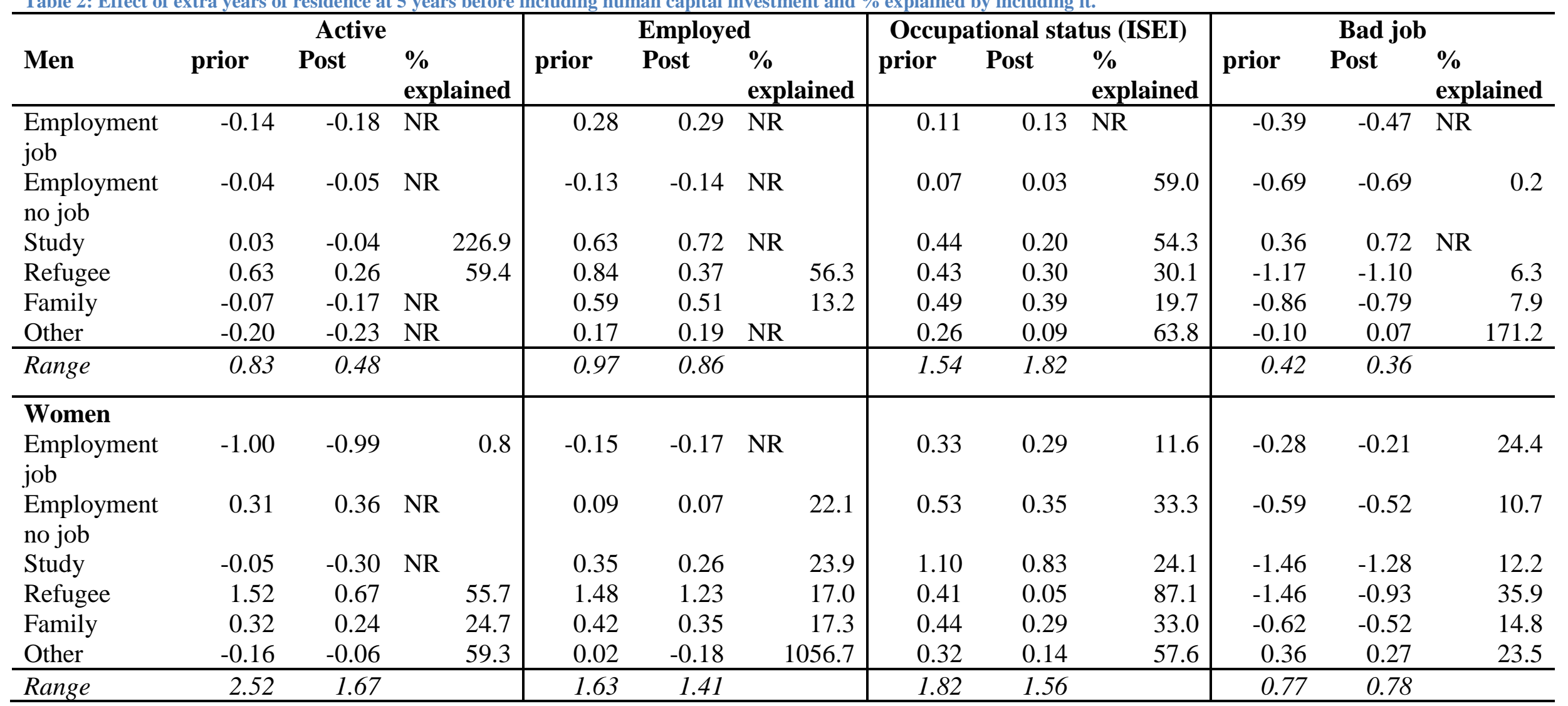

Note: NR indicates the effect was not reduced. This table shows the estimated effect of an extra year of residence from a model controlling for socio-demographic controls, country of residence and region of origin characteristics, and the \% of that effect that is explained by including information on equivalising qualifications, naturalisation,

language skills and whether the respondent attended training. 